\title{
Prefatory remarks
}

The new Silk Road Somewhere in the beginning of my sabbatical stay in Berkeley I called my 92-year-old mother and spoke to her about Silicon Valley. She misheard me, and asked whether I was doing research on a silk valley, wondering how this connects to my research. I paused, and had to admit that she was not entirely mistaken. Perhaps I was indeed investigating the new Silk Road; the one leading us into cyberspace territory, enabling the creation of added value based on trading personal data against online services. However, I told her that I was talking about silicon, not silk. 'Ah', she said: 'is that some kind of medicine?' This, again, stopped me in my tracks. Are the integrated circuits that crowd silicon chips not a kind of medicine; a pharmakon that can be either poisonous or healing, depending on how it is integrated in our life world? My mother is quite sharp and well aware of the role played by information and communication technologies, though she admits that she is not planning on opening a Facebook account any time soon. She just missed how much of our current world has originated in this particular part of California; how silicon became the new gold and technology developers the new gold diggers, even if we must not forget that, in the end, it is the business models and our data that have turned silicon into gold.

The new gold One day someone should write a follow-up of Joan Didion's Californian memoir Where I Was From. In it, Didion describes the mythology of the Western Frontier that serves as a foundational narrative for Californian identity, chronicling 'the crossing' into new territories in the 17th and 18th centuries, the gold diggers' mentality that shaped San Francisco in the 19th century, and the building of the cross-country railroad, thus explaining the peculiar concoction of individualist pride, entrepreneurial daring and dependence on the federal government that defines California even today, according to Didion. At this moment, however, anyone anywhere can trace herself back to the transformative inventions somehow connected to Silicon Valley. The large technology companies of Silicon Valley that form a bristling ecology together with a steady surge of start-ups, are reconfiguring our 
everyday life worlds, while constructing the information and communication infrastructures that shape the flow of information, goods, services, people and capital around the globe. This is where our world is built. In fact, it seems that a surreptitious shift is occurring towards hardware, notably 'softwired' interconnected 'everywares' such as wearables, robots, creative 3D printing, and so on - entailing simultaneous disruptions and movements in the geography of invention (MIT's Center for Bits and Atoms, Maker Faires everywhere, San Francisco start-ups on the nexus of hardware and software, Rethink Robotics in Boston, Japan moving head-on into companion robots).

The extended mind Technology was always a part of us, as philosophers of technology, archaeologists and anthropologists have tried to explain, and by now even lawyers acknowledge how literally we should take this. As The New York Times recorded in June 2014, unwittingly endorsing Andy Clark's view on the mobile phone as a part of our extended mind: ${ }^{1}$

Chief Justice John G. Roberts Jr, writing for the court, was keenly alert to the central role that cellphones play in contemporary life. They are, he said, 'such a pervasive and insistent part of daily life that the proverbial visitor from Mars might conclude they were an important feature of human anatomy.'

Clark argued that we should give up on understanding the human mind as something that is contained within our 'skinbag'. Taking the example of our mobile phones he demonstrated, even before the massive uptake of the smart phone, that our minds include the cognitive resources that extend them: from written text to wearable communication devices and critical infrastructures that run on the analysis of our behavioural data.

Mindless data-driven agency: a new animism So much has already been written on the ethical, social and legal implications of the emerging information and communication infrastructures that I hesitate to add my bit. However, I believe that it is crucial that we confront our new world by facing the new animism it provokes. With the notion of 'new animism' I refer to the fact that our life world is increasingly populated with things that are trained to foresee our behaviours and pre-empt our intent. These things are no longer stand-alone devices; they are progressively becoming interconnected via the cloud, which enables them to share their 'experience' of us to improve their functionality. We are in fact surrounded by adaptive systems that display a new kind of mindless agency. Brain inspired, neurosynaptic chips have been prototyped, that are typical for the way long-existing technologies such as artificial neural 
networks and miniaturization of ever more integrated circuits on silicon chips combine to simulate one of the most critical capacities of living organisms: unconscious, intuitive and on-the-spot pattern recognition. The environment is thus becoming ever more animated. At the same time we are learning slowly but steadily to foresee that we are being foreseen, accepting that things know our moods, our purchasing habits, our mobility patterns, our political and sexual preferences and our sweet spots. We are on the verge of shifting from using technologies to interacting with them, negotiating their defaults, pre-empting their intent while they do the same to us. While the environment gets animated, we are reinventing animism, ready to learn how to anticipate those that anticipate us - animals, fellow humans and now also smart, mindless machines. There is animation and animism, but also animosity. Between individual freedom and pre-emptive artificial environments (guessing our preferences before we become aware of them), between individual persons and their smart appliances (the fridge ordered what was to be expected, but we want something else), between a person and her digital assistant (who may have different purposes), or even, between negotiating digital assistants of friends, colleagues or family members (acting upon the inferred interests of their patrons). Not to mention the animosity between those who are paying for the assistant (the insurance company?) and those that employ it, or the government that claims the need for a viable 'information position'.

The most interesting, disrupting and intriguing aspect of our new world concerns its mindless animation, its unconscious - or should we say a-conscious - calculations of our future states and behaviours. We are invited to learn to deal with an artificial world, 'peopled' by a myriad of artificial agents that are becoming more and more smart and unpredictable. We might develop emotions about these agents, especially if embodied (as with robots). They are learning to 'read' our mind, including our fears, loathing, desires and addictions. When I was hiding in my writer's retreat in the Berkeley Hills, my host regularly dropped in to check how I was doing. He told me that during his own sabbaticals he had experienced the joys of seclusion, but also confronted the need for human contact, which seems pivotal to confirm one's own existence as a human person. I wondered, later, how I would have fared if it were an intelligent, personalized robot companion that checked on me. I wondered about my mother's caretakers: what if they were soft, sweet and capable nurse-robots instead of human nurses? What if our children cannot afford a human nanny or a crib to care for their infants, leaving their children in the hands (and arms) of robot nannies? What if these robot companions, enhanced with machine learning and access to Big 
Data Space, do better than the humans they replace? Will it turn us into machine-reading agents, as we need to understand how they understand us to deal with them? What will a capability to read the mindless mind of artificial agents do to our own minds? Could it be that being cared for by humans will eventually become a privilege for the rich and famous (those with clout in the cloud); or should we expect the opposite, where only those who can afford the costs of security upgrades have the pleasure of fine-tuned robotic companionship?

Between Brussels and New York This volume was initiated in 2009, during my research sabbatical in New York City, where I participated in the cutting-edge NYU privacy and technology research group of Helen Nissenbaum, as well as the SUNY techno-science philosophy seminars of Don Ihde, at Stony Brook, Long Island. I take this opportunity to applaud and celebrate the work of both Helen and Don, however different, and to thank them for 'having' me during the fall of 2009. The change of scenery between Downtown Manhattan and Stony Brook was tantalizing; the intellectual perspectives, student backgrounds, urban and non-urban landscapes were miles apart, making the back-and-forth all the more interesting. It confirmed my intuition that philosophical reflection on technology as an enabler of science and society is pertinent, against the common sense of seeing technology as merely an implementation of scientific insight. It also confirmed my intuition that analytical philosophy contributes to clarifying concepts, methods and different points of view, while enabling ethical inquiry into the implications of privacyinvasive ICTs. Finally, it reinforced my deep appreciation for the Brussels School on privacy and data protection - if such a label fits at all - of which I find myself a radical and unruly member and proponent. This is my way of paying tribute to Serge Gutwirth, head of the research group on Law Science Technology \& Society (LSTS) at Vrije Universiteit Brussels, and his colleague, Paul de Hert, who staged the famous annual Computer Privacy and Data Protection (CPDP) conferences in Brussels, and Isabelle Stengers and Bruno Latour, who were copromotors of an adventurous research project on the responsibilities of scientists which I joined in 2002. The latter project introduced me to the notion of correlated humans, soon reconceptualized as correlatable humans, highlighting the continuities and discontinuities between statistics and, notably, machine learning. The difference between both is that whereas statistics is instrumental in enabling machine learning, we must acknowledge that machine learning is a different thing. It thrives on the combination of 'perception' and 'action' of machines, using statistical inferences as feedback to learn about the inferred consequences of one's 
actions. If statistics is considered by many mathematicians to be without the boundaries of mathematics, machine learning is way out of bounds. It seems closer to empirical testing than to axiomatic reasoning, but we should not forget that it is only capable of testing patterns in data sets. However big these sets are, they are not what the data refer to, nor what the inferences refer to. In other words, though we may be presented as correlated humans by machine learning techniques, we are fundamentally correlatable humans. One way or another. For a lawyer, the latter statement is crucial. Machine learning, data mining, Big Data analytics and similar techniques of artificial intelligence are incredibly advanced compared to the rule-based algorithms of old school artificial intelligence. But all depends on the constraints of the hypothesis space, on the extent to which algorithms can be tweaked by noise or random interference and - obviously - on the framing imposed by alternate algorithms. Considering the effects of employing one computational technique rather than another, we must urgently learn to contest the decisions they take. Just like human judgement, they are not objective, but, other than human judgement, it is not obvious that we can argue with them and put our finger on the operations that informed the decisions. That is why this volume is focused on data-driven agency and its implications for the Rule of Law.

BerkeleyHills When I decided to situate my 2014 research sabbatical close to Silicon Valley, I also chose to organize the sabbatical as a writer's retreat. I attended the SOLID conference for technology developers on the nexus of hardware and software in San Francisco. ${ }^{2}$ I spoke at the Robotics and New Media symposium at UC Berkeley, ${ }^{3}$ on the invitation of Shanti Ganesh, who combines cognitive psychology and brain research with an acuity that is rare within the confines of empiricist research into the relationships between brain, mind, body and society. But, foremost, I retreated into my cottage in the hills of Berkeley, a so-called 'in-laws', located behind the house of Luisa and Manuel, my hosts. To do my daily shopping or reach the urbanity of Berkeley and San Francisco I had to first walk downhill for half an hour (a very healthy retreat as you can imagine) and this prevented me from giving in to diversions, forcing me to stick to the writing process. A rare luxury. Solitude enables the writing process in a way no other constraints do, despite the rampant connectivity that can easily turn solitude into an illusion. When I returned to the text of 2009, which was left untouched due to five years of other obligations, I was surprised to find that the opening narrative was hardly speculative anymore. I wondered whether it was at all still relevant. Most of the chapters have been rewritten entirely, 
taking in five years of research and five years of socio-technical development. But in the end the narrative remained largely unaltered. I realized that it focused on the notion of data-driven agency, even if not explicitly coined as such. This is now the central theme of the volume.

Law and computer science Since 2011 I have had the privilege of holding the Chair of Smart Environments, Data Protection and the Rule of Law. This Chair is located at the institute of Computing and Information Sciences (iCIS) at Radboud University Nijmegen, where Bart Jacobs entitled his inaugural lecture 'The Computer Under the Rule of Law' ${ }^{4}$ I am now a lawyer teaching about law in cyberspace to master students of computer science. This has influenced my take on the relationship between smart technologies and the end(s) of law. I have become convinced that computer science and law share a sensitivity to architecture, an awareness that changing a rule in one part of the system has immediate as well as indirect consequences for other parts of either law or a computing system. To sustain our artificial worlds, both institutional and artefactual, this sensitivity is critical. Similarly, computer engineering and law share the need for pragmatic solutions that cross bridges when they get there and work from the legacy of existing constraints. Both are geared to solutions while aware of the need for constructive attention to systemic constraints, even if that may sometimes disable solutions that are attractive from a short-term perspective. Working in a computer science department has also sensitized me to the differences between law and computer science, notably the inherent ambiguity of law as a text-based discipline that thrives on human language compared to the need for disambiguation inherent in disciplines that are built on digital technologies. Taking into account that our world is progressively reconfigured to cater to the needs of digital technologies, this difference remains crucial and requires positive attention to be preserved against Big Data worship and other mistaken beliefs in the objectivity of either data or what is inferred from them. In the third part of this book I take a deep dive into the central and often incompatible ends of the law: justice, legal certainty and purposiveness. I follow Radbruch in claiming that for a normative framework to qualify as legal it must at least be 'reconstructable' as aiming for these three ends, while admitting that their interrelation and articulation will often require us to strike a balance. I also vouch for EU data protection law as the only way to halt unbridled and mistaken trust in data-driven agency, arguing against recent calls for discarding both limitation of data collection and purpose binding. Considering the growth of Big Data collections, I believe that within less than five years the question will not be how to 
collect as much data as possible, but how to 'select before you collect' and how to correct, connect, delete, anonymize or pseudonymize personal data. From a business and government perspective the question of life-cycle management of data will become the greater challenge, as this will be preconditional for the functionality and the security of data-driven intelligence. From a fundamental rights perspective it is critical to recognize the plurality of rights that are at stake, instead of reducing data protection to informational privacy. Much more is at stake.

The end(s) of law This volume builds on the fact that modern law has been contingent upon the information and communication infrastructure of the printing press, explaining how the Rule of Law similarly depends on the affordances of proliferating copies of identical text. Data-driven architectures operate at another level that sublimates rather than externalizes the normativity that directs and coordinates our interactions. The hidden complexity and invisible inferences that increasingly and seamlessly adapt our environment constitute a new - digital - unconscious. We need to urgently come to terms with this, reinventing legal articulations capable of reinstating justice, legal certainty and purposiveness in the upcoming onlife world.

The end of publishing this book is to sensitize readers to the urgency of the task ahead, sharing provocations, analyses and a coherent framework to face life in a world beyond offline and online. A framework that is compliant in the sense of bending with the changing socio-technical landscape and solid in the sense of providing a backbone that is reliable, tested and contestable while still affording a critical stance. If we do not learn how to uphold and extend the legality that protects individual persons against arbitrary or unfair state interventions, the law will lose its hold on our imagination. It may fold back into a tool to train, discipline or influence people whose behaviours are measured and calculated to be nudged into compliance, or, the law will be replaced by technoregulation, whether or not that is labelled as law.

Pre-emptive computing systems may thus trigger the end of law as we know it, but this is not necessarily the case. All depends on how we design, construct and develop our information and communication infrastructures and how we engage with the mindless agents that will 'people' our onlife world. In the end, this book is about building legal protection into our artefactual environment, reinventing recalcitrance - as my dear colleague Antoinette Rouvroy might say - as well as the means to generate values and added value in a shared onlife world that celebrates and affords both democracy and the Rule of Law. We want to have our 
cake and eat it too. To the extent that we continue to bake fresh cakes this is possible, but we must acknowledge that data and even information are not edible.

This book is an inquiry into the implications of smart technologies for the mode of existence of the law, that is, for how current law fabricates our artificial, institutional and artefactual environment. The question is whether modern law is capable of protecting us against undue transparencies and, if not, how we might reinvent the protection we need to flourish as individual human persons that are forever mediated and reinvented by the technologies they invent. 